\title{
Interview Talk as Professional Practice
}

\author{
Carolyn D. Baker
}

Graduate School of Education, The University of Queensland, Brisbane, QLD 4072, Australia

\section{Greer Johnson}

Faculty of Education, Griffith University, Mt. Gravatt Campus, Brisbane, QLD 4111, Australia

Conventional understandings of interviews with teachers or other educational participants have treated interviewing activity as data collection, and interview responses as reports on the realities of professional practice. This paper proposes that interview data can be analysed differently when interviews are studied as instances of 'language in education' themselves. The interview can be seen as a site of professional practice, not just reflection on practice, in that such interviews contain courses of questioning and methods of accounting that are reflexively part of the generation of educational knowledge. Working from transcripts of two interviews with a beginning secondary school teacher, we focus on the ways in which language is used interactively to recast professional knowledge and discourse.

\section{Analysing Interview Materials}

There is a range of approaches available for the analysis of interview data. These approaches are linked to various conceptions of the interview in the social sciences. Probably the most conventional perspectives on interviewing in social science and educational research are those which treat the interview as a method of data collection, and the contents of answers as the data. Interviewees are asked to provide reports or descriptions about interior states or external events in the world outside the interview. This methodology often presupposes that some reality - knowledge, beliefs, stories, perspectives - preexists the interview. This approach provides for coding-based analysis of ideas and themes in the interview transcripts. The logic and procedures of such an approach are summarised in numerous texts: see for example the concept of 'topical interviewing' presented in Rubin and Rubin (1995), whose chapter on data analysis explains the way in which themes are found and fitted to coding categories. In this kind of analysis, the questions and the interviewer disappear. Selected elements of the interviewee's answers count as the data, and these elements are lifted out of the immediate context of their production. They are, in effect, decontextualised. Smith (1991) has described how sociological analysis often extracts items from original accounts and enters them into new and different arrangements of knowledge.

Another view of interviewing and analysing interview data recognises that interviews necessarily involve social-interactional matters, and that it is not possible to quarantine or purify the interview. For example, Briggs (1986) is critical of the conventional view sketched above, and writes about the necessity to appreciate the specific sociolinguistic frame of interviews and the participants' 
communicative norms and interpretive frameworks, in order to get at the meaning of the interview talk.

Looking for metacommunicative elements enables the researcher to base his or her interpretation on what the speaker is saying, not only about 'the world out there' but also about the researcher's own words and the manner in which the utterances as a whole relate to the circumstances of their production. (Briggs, 1986: 107)

This view of interviewing is interested in the metacommunicative elements in so far as they affect the interpretation of the interviewee's meanings. That is, while this perspective does recognise the interactional and communicative (and often intercultural) context of production, what counts as the data are the respondent's meanings. Briggs comments: 'The basic task is [...] trying to figure out what the devil that person was trying to get across' (1986: 107). Similarly, this approach presupposes an underlying reality to be more or less adequately uncovered in the interview, and there remains a concern with 'correct and/or exhaustive' analysis (Briggs, 1986: 110).

The idea that respondents' answers represent their 'interiors' (knowledges, beliefs, motives, meanings) or give valid descriptions of 'exteriors', or can do so under ideal conditions, treats language as a transparent medium for expressing and exchanging ideas (Kress, 1988; Silverman, 1993; Baker, 1997). A situated perspective on language use recasts this understanding in important ways. Language comes to be seen as a resource for describing states and assembling social realities in particular, setting- and listener-relevant ways. Interview talk cannot be viewed naively as more or less truthful or complete or valid in some $a$ priori way.

What this means is that interviewing may be understood as a particular form of enacting or displaying one's knowledge of cultural forms. How people speak to each other - what the interviewer asks, for example - is as much data for the analyst as what the respondent says. Asking questions of another person always calls into play particular knowledges, power and values connected to particular social memberships. Questions are never neutral and are powerful means of calling on members' cultural repertoires of ways of speaking. What this calls for is a very different approach to analysing interview data. As Silverman (1993:108) has put it, 'By analysing how people talk to one another, one is directly gaining access to a cultural universe and its content of moral assumptions'.

For the most part this last approach to interpreting interview data has not predominated in educational research. Most educational research interviews have worked under the presuppositions of the earlier perspectives outlined above. For the most part, the activity of interviewing, and correspondingly the activity of analysing interview data, have been viewed as methods of inquiring into persons' interiors or their exteriors. The alternative is that the activities of interviewing be analysed as interactional events in the social world which in themselves provide telling evidence of how people make sense of each other and what resources they use to do this.

A powerful way of refashioning the analysis of interview data is to attend to practices of accounting as integral parts of sense-making procedures. People are 
continually accounting to each other for the activities they perform, that is, they offer or imply reasons, justifications, motivations, and outcomes of their courses of social action. Looking for and examining accounting practices are powerful means of accessing the moral dimensions of social behaviour, settings and action (Silverman, 1987, 1993; Mercer \& Longman, 1992; Baker \& Keogh, 1995; Baker, 1997). As we will show with the materials in this paper, teachers' talk about professional practice is observably 'moral' work.

These accountings point to the presumably shared moral grounds of activity and are inextricably part of people's displays of cultural competence. Attention to accounting as a form of cultural practice allows interview talk as well as many other forms of talk to be understood as 'culture in action'. Hester and Eglin (1997a: 19-20) argue that culture resides 'in' action, specifically 'in' people's uses of cultural resources such as membership categorisation. While this paper does not undertake a membership categorisation analysis, there are clear links between the categorical incumbencies of the participants in the interview and the Discourse of moral responsibility that is generated in the talk.

\section{An Application to Interviews with a Teacher}

In the second part of this paper we apply these observations about perspectives on the analysis of interview data to materials drawn from a study of beginning teachers' discourses and practices undertaken by Johnson (1996) with beginning English teachers across two years: their postgraduate teacher education year and their first year working as qualified secondary school teachers. Although the application in this paper is to interview talk with an English teacher, the concepts and analysis have application to research with teachers more broadly.

This study was concerned with the ways in which beginning English teachers drew on different ways in which the school subject English could be practised, in particular which kinds of literacy the school subject English could be promoting. The interest in the beginning teachers was in the various D/discourses (Gee, 1996) about English teaching and literacy from which they drew in their writing and speaking as well as in their classroom work with students.

Gee (1996: 131) argues that:

A Discourse is a socially accepted association among ways of using language, other symbolic expressions, and 'artifacts', of thinking, feeling, believing, valuing, and acting that can be used to identify oneself as a member of a socially meaningful group or 'social network', or to signal (that one is playing) a socially meaningful 'role'.

Discourses are recognisable (in discourses with a lower case $d$ ) as 'connected stretches of language which hang together so as to make sense to some community of people' (Gee, 1996: 90).

The theoretical framework for the (Johnson, 1996) study was, broadly, poststructural. What this meant in this case for the study of teaching was a reorientation of standpoint with regard to the teachers and their talk and action. In this paper the teacher's talk with the interviewer is analysed to show how moves in professional practice can be accomplished through talk. The talk itself 
is viewed as representing and constructing different positions within a Discourse of moral responsibility. Unlike the prevalent developmental models in which growth towards teacher expertise is the goal set out for and by the beginning teacher, poststructural models see 'expertise' as an ability to notice and make sense of the various Discourses in which one is successively engaged. Correspondingly, professional experience is seen no longer as either unified, or analogous to that of others, or linearly acquired. Teachers can account for the fact that they practise in different and even conflicting ways in differently situated moments. 'Professional experience' is also not confined only to 'real' (i.e. classroom) practice, but is seen in many sites where Discourses about teaching are produced or encountered.

Recalling the commentary above on the use of interviews in educational research, interviewing teachers has usually taken the form of asking teachers to report on their knowledge, beliefs, attitudes and practices. These reports on interiors and exteriors become 'the data'. The beliefs or other contents are extracted from the spoken words and discussed as themes or patterns of ideas. What is not analysed is the actual situation of the interaction in the interview itself.

In the study from which this paper draws its materials, a very different view was taken of interviewing and of interview data. In this study of six beginning English teachers over two years, research interviews took the form of post-lesson conversations in the classroom, on four occasions with each of the six. The researcher in this study was the English curriculum lecturer and practicum supervisor of the students in the first year. Then the relationship changed to a purely research relationship in Year 2. After most of the lesson observations, and usually on the same day and as soon as possible after the lesson, conversations with the teachers of an average length of half an hour were audio-taped. The researcher and the teacher talked about that particular English lesson and about teaching in general. The conversations varied from teacher to teacher, but generally as the year progressed the teachers became more active and talkative in the interviews (they were able to initiate conversations rather than wait for researcher initiatives) and the conversations became longer. These conversations were unstructured in the sense that there was no fixed schedule of questions, but the focus was always on the work and ideas of the beginning teacher. The teachers were invited to talk in their own words about their teaching and the conversations were often opened and closed with the question 'Is there anything [else] you'd like to talk about?' During the conversation the researcher asked questions referring to similar conversations and correspondence over the two-year research period, and from other observations of the teacher's lessons.

\section{Interview talk as metacommentary}

The study generated a 'post-personal' perspective on beginning teaching in that the emphasis was shifted from the more conventional research interest in teachers' views, beliefs, experience and other reports of 'interior' or 'exterior' states of affairs, which are sometimes formulated as studies of teachers' 'reflection' on their practice. The shift was toward studying how teachers accepted, adapted, called on and refracted the various Discourses about English 
teaching that were made available to them during the course of teacher education and their first year of independent practice in the schools. The Discourses included post structural approaches to the teaching of texts (which they named as critical literacy) (Johnson, 1996). Such Discourses are sense-making resources with which the teachers could talk professionally about their work. The route to this was to attend to how they accounted for their practice in a number of speaking and writing activities, including post-lesson conversations with the researcher.

\section{Interview talk as accounting}

The work of Silverman (1987) in analysing talk among professionals, parents and teenage patients and subsequent work by Baker \& Keogh (1995) on parent-teacher interviews concerning teenage secondary-school students found that the very nature of the talk about parenting or teaching practice may provoke interviewees into taking up morally responsible positions for their practice.

Certainly, the agenda in the post-lesson conversations between the teacher and the researcher in the present study was that the teacher would account for his or her practices during the lesson and his or her teaching generally. With teachers, as is the case with the parents and teachers in the Baker and Keogh (1995) study, there is a high probability that they will account with moral responsibility because of their assumed duty of care towards those in their charge.

\section{Interview talk as action in pedagogical space}

There is an important difference between this work with beginning English teachers and interviews reported in Silverman (1987) or Baker and Keogh (1995). The difference is in the explicit understanding between the teachers and researcher that the purpose of the talk was to critique and perhaps re-theorise practice rather than defend it, that is, to move the teacher's practice and theory forward. It was prospective talk as well as retrospective talk. And as we develop below, it was more than reflecting, and more than accounting. The post-lesson conversations involving the researcher and the teachers were another form of practising their respective professional knowledge. Talking about teaching was action in pedagogical space: a place for reformulation, renewal and recasting subject English as it could be enacted.

\section{Analysing Teacher Interviews Differently: A Demonstration}

One function of the post-lesson conversation in this study was to have the teachers re-theorise past as well as future practice. In this section of the paper we demonstrate the analysis of these interviews as 'actions in pedagogical space'. The following extracts come from post-lesson conversations with a teacher we call Alan. These conversations always followed observations of his English lessons during his teacher education year and his first year of teaching. As Alan had done his preservice teaching practice at the school where he held his first teaching appointment, and as he had been involved in the research over nearly two years, he was familiar both with the research methodology and with the school context. Therefore by the time these interviews took place in the second year of the study, the talk flowed very easily without need for direction. 
These extracts also show that the researcher was relatively quiet throughout the conversations, supplying some formulations and confirmatory utterances as well as some clarification requests and other questions. The researcher had been Alan's English curriculum lecturer in his teacher education year and Alan had agreed to stay with the study into his first year of teaching. They therefore have common professional knowledge to draw on, and we can see that Alan's accounting is done within an appreciation of who his interviewer is and what she knows. However although the researcher's participation in the talk is usually minimal in length, the work that is done through these interjections is very consequential for what Alan then does in his talk.

In the first extract the interviewer makes a summation of Alan's prior talk to the effect that he is uncomfortable with teaching mixed genres, which is a current approach in English teaching. Alan replies with a twofold concern, first that the students are in danger of being marked down for not keeping within the confines of mandatory generic structures, and that they are unsettled and disadvantaged by an unfamiliar pedagogy.

Alan: You've given me a real problem because um you're supposed to mark them as if everything is $[(\mathrm{a})]$ genre that's another problem with teaching the genre-based thing it restricts the kids because when it's marked you say 'Oh they've confused their genre' but they don't know what they're writing. Now that's not fair because there might be a very smart student who's intentionally mixed

R: $\quad$ The genres

Alan: Mixed the genres so I think it's a bad thing mnn

R: $\quad$ So you see a conflict there?

Alan: Hmn well what do you do when you get the piece in because particularly for something that's going to be looked at by the [external assessment board] because there's every chance you see 'Oh this is a smart kid' you know the kid may have mixed the genres you hand it in to the panel and they say 'Oh no they've got no idea they can't write within a genre'

R: So am I right in assuming then that you wouldn't, don't feel, comfortable then teaching them to write mixed genres?

Alan: I'm convinced they wouldn't cope which I think is a shame for most of my students um and because it's a function of the way they've been taught everything they've just been taught you know you write the short story - you write the essay you write the this or that and so I'd say 'Well what's this? What's this thing? (Interview 1, 046-057)

This interview talk can be described through a number of overlapping layers of interpretation. It could be treated as a reflective report about his teaching, in that he is describing how he feels and outlining facts about the conditions of teaching, learning and student assessment (as in the conventional view of interviewing described earlier). However looked at through the different terms we have introduced, the talk can be seen first as engaging in interactive metacommentary. To the extent that both speakers are using the vocabularies of genre pedagogy they are refracting Discourses about English teaching. Secondly, 
we can recast the data to see it as a form of Alan's accounting for why he feels uncomfortable. In this accounting he is calling on a version of moral responsibility to his students. We can identify this as a Discourse of moral responsibility. That version of moral responsibility, he implies, prevents him from changing his practice. In speaking this way he consolidates his reason for continuing past practices. Because he produces a reason for not changing, he is acknowledging the possibility that he should change. This is talk and action in the moral domain, which extends to the relationship with the interviewer.

More powerfully, however, when Alan says, 'You've given me a real problem' and then proceeds to address that problem, we see how consequential the work of the researcher is in occasioning a working through of the problem. This may or may not be the only time that Alan confronts and deals with the problem, but it is evident that he did confront and deal with it here. This talk is more than accounting, more than a defence of practice, it is a recasting of practice because he is rehearsing viable and nonviable, hypothetical courses of action. This is an instance of talk as social action, as a move in professional practice, not talk as merely referring to social or professional action. The researcher's apparently minimal interjection, 'so you see a conflict there' sets off a second pass by Alan at the problem, this time focused on assessment. During the second pass Alan shifts to a different position in the Discourse of moral responsibility. From this position his talk focuses on his dissatisfaction with past teaching practices, paving the way for the consideration of new pedagogical practice in the future.

Important emphases in his talk were his colleagues and the students. His membership in the Discourse of moral responsibility prompts his reconsideration of his classroom practices. These practices were accounted for, as we will show, within an over-riding concern with moral responsibility. Interviews with teachers whatever the topic could be expected to be replete with accounting work, and our analysis of the interview talk with Alan shows how this could be investigated with other materials as well.

We turn now to extracts from an interview with Alan held three months later, following another lesson observation. Quotations presented for the most part follow a chronological order. However, in these interviews the interviewer and Alan double back in their talk, follow circuitous paths and revisit topics in various ways. Accordingly in the analysis we do not suggest a linear development of practice. The sections that follow show different aspects of interview talk within the Discourse of moral responsibility.

\section{Accounting for colleagues}

Early in the second interview Alan shows that he feels some responsibility towards the other teachers. Alan had introduced a new way of teaching poetry to his school, the poetry journal, which is based on literary theories unfamiliar to some of his colleagues. He agrees with the researcher that in writing the poetry journal he had to 'accommodate' the ways in which the other teachers have always taught poetry. He goes further to explain:

there's no way we would have had sociocultural [critical literacy] comments because they [the other teachers] just aren't - no - it's um, we still 
have people who use [...] that are doing lit[erary] crit[icism] um poetry as poem as artefact, stuff, with single meaning [ ...] (Interview 2: 011)

Much later in the second interview he confirms the dominant theoretical positioning of the teachers as '... we're not reader response, we are new critical' (Interview 2, 417-425). At this point in the conversation it is not clear if the 'we' includes Alan. This recursive work with pronouns 'we' and 'they' could indicate a process of working through his own professional position in relation to the other teachers in the school. He had accommodated his colleagues in the past but now shifts his thinking towards introducing a new pedagogical practice that would enable his colleagues to succeed:

What amazes me though is that I think it [the poetry journal] would have been outrageously successful, even if taught in the other way, in reader response, it would have worked just as well, and they probably would have (pause) yeah they [the other teachers] would have succeeded I think. (Interview 2: 018-19)

This is not merely a report about 'what happened'. It is an account that recognises his responsibility as a professional and a colleague to introduce teaching practices that are successful. He conveys that the poetry journal did work well, and that it would have worked well even if taught another way. It is in the talking that he finds and presents this insight ('what amazes me though') as an additional insight pertinent to this listener. What amazes me though a preliminary to further discussion about practice.

\section{Accounting for students}

Related to his concerns about the difficulties the teachers might have in negotiating unfamiliar literary theories are his concerns with how he and the students coped with change. The difficulties are associated with teaching some of the practices required by the poetry assessment task. Alan shows his awareness of the difficulties both he and the students have with less traditional approaches to textual analysis. He posits reasons for his students' objections to textual analysis of a translation/imaginative recreation of a stimulus text:

R: So you mentioned that these kids, the more academic sort of kids in Year 12 , were not really interested in the notion of refuting positions.

A: Well I think they've had, because they're academic, they've become inculcated with the way their teachers look at literature, and so, that was why they were cranky with that video because they said, 'Why are they taking so much from that video? They should be looking at the poem and the words of the poem'. It sounds very much to me as literature as artefact, and I just let that go but I think it showed, you know, the academic kids, they've already been given that, and see $I$ was given that too, it's hard for me to move from there because I was taught that way too. Although I don't think we had it as artefact because we were allowed to - I love the front of that anthology, that quote of T.S. Eliot's himself, and that's why I made the anthology up, and it's got this [...] (Interview 2, 020-27)

The researcher's initiating comment in this extract recalls a previous point 
mentioned. This is a device to get more talk on a point of interest to her. At the same time it has invited morally responsible accounting because it implicitly provoked the teacher into giving the reasons that the students have a preference for one kind of analysis of poetry over another. Again, the interviewer's move is consequential in so far as it gives Alan the opportunity to come at the same issue from the students' perspective. Alan's account is constructed in terms of the intergenerational nature of his own reading and teaching practices. At this point in the conversation Alan acknowledges that the students are aligned with the other teachers' traditional methods of teaching poetry. Alan realises that he too is positioned to teach poetry by the way he was taught at school. He has now circled back to the point that the researcher can understand that he is included in the 'we' who prefer traditional approaches in teaching poetry. The effect of keeping him talking about these students seems to be that he has found a rationalisation for not changing his own practice in teaching poetry. He says: It's hard for me to move from there because I was taught that way too. His accounting is not just talk about past social actions situated elsewhere. It is a social action in so far as his words contain the possibility and the desirability of 'moving from there'.

\section{Going places}

At another point in interview 2, the success of the poetry journal that Alan had initiated is discussed using a journey metaphor that Alan introduces and the interviewer extends.

R: Yes, the previous way you did it

A: Yes and it's all see that's [grade] 11 as well and it's 10 and 9 and 8 and all they do is poetry anthologies, and the problem with that is, that everyone goes and picks up the poems that they like which is fine but you never get to get the class together and discuss poetry, and so often the kids who are nowhere in poetry at the beginning, are in Grade 12 and are nowhere in poetry at the end.

R: So you feel they are somewhere, now? (Interview 2, 041-047)

Alan's accounting shows that the 'wrongs' or bad teaching and learning practices are implicit: that the listener at least understands that 'the class never getting together and discuss[ing] poetry' and being 'nowhere in poetry' are being judged as morally undesirable classroom practice. In the follow-up response/question the researcher co-constructs a version of good practice, replacing nowhere with somewhere. The reconstruction of good practice recognises an implicit somewhere. This somewhere is then elaborated by Alan, and kept going by the researcher:

R: So you feel they are somewhere now?

A: Well people like Jason Lehmann, who I was talk- he- you heard from the way he read, what his English is like, and he's coped, which is really exciting.

R: And the girl over there with the uniform on

A: Anne, yes, she's [a school leader]

R: She seems to have, done really

A: Well she's a genius yes.

R: She's really pushed (ahead) 
A: Yes and that's been the other, the other really wonderful thing about it is it caters so well for individual differences [...] different levels coming out all at the same time

R: There were

A: And that was really exciting

R: What about genre? You mentioned [...] (Interview 2, 047-54)

Later in this same interview, Alan was describing a lesson that the researcher had not observed, and which was not connected with the poetry journal. The researcher turned the talk back to the lesson that she did observe immediately prior to this interview. Accounting for what a colleague did observe is different from accounting for what she did not observe. The researcher's turn, then, is provocative of this further accounting.

R: And then if we skip to the lesson that I did see, in that one you were doing [two parts of the poetry journal]

A: Yes and I'd more or less given them, I'd already given them a way to successfully write up [the poetry journal]-, see all the fun had stopped by then and it was how to get this thing right to hand in [for assessment][...] Everyone was really depressed by the end of the unit because there was so much fun in the first few weeks of it and then when it came down to assessment it really depressed everyone because they had to (pause) you know, stop all this poetry stuff and hand something in for assessment. (Interview 2, 360-367)

Alan sets up a marked contrast between what the researcher did and did not see with his choice of the words 'fun' and 'depressed'. His further description of what the researcher literally did not 'see' is signalled by see what it came down to in the end. His own moral position as empathetic with the students' experience of disappointment is simultaneously produced. The story continues:

[...] see what it came down to in the end, is no matter what happened in [the 'fun' part of the poetry journal] you had to come up with a [final critical analysis] which said this - this is the story of the poem; this is what the poem is telling you [...] what is the theme of the poem? What does it mean and you could either say this [...] or you could say this [...] you'd have to think up a theme and then you'd have to discuss how all of the poetic, all of the poetic techniques which have been used to further that theme or to forward that theme so you talk about the use of symbols and [...] So I thought that was very, very, very old fashioned. (Interview 2, 387-399)

The accounting in this section of the conversation leaves no doubt that both teacher and researcher would agree that a very old-fashioned method of assessment was used in the poetry journal, implying at least the possibility of a new-fashioned method waiting in the wings. This move also effectively relieves both teacher and in this case researcher from moral responsibility for the failure, as neither would have approved of this method of assessment. Not only were the students no longer going anywhere, the assessment is said to have closed down all the fun. Substantively, Alan conveys that what was supposed to be 
new-fashioned and innovative, was really in the end no different from old-style poetry analysis.

Alan offers both the good news and the bad news about the poetry journal. As his story unfolds for the researcher, he talks himself toward being open to change in practice. The good news, coming first, does not logically call for change. The bad news, coming later, is 'actionable' in this context. The researcher wants to hear the story and her involvement in the talk (as speaker and as listener) is a consequential intervention in Alan's professional practice. Alan's talk could also be a consequential intervention in hers in that she could add Alan's critique of the poetry journal to her discussion of English teaching with preservice and inservice teachers.

\section{Not the end of the story}

In this fourth part of the article we propose a further development of this perspective: to treat interview talk as social action in that such talk can reshape practice. In talking about practice, interviewer and interviewee can deconstruct and prospectively, imaginatively, reconstruct the grounds of professional activity.

The topic and the talk by now share a trajectory: towards some solution to the recognised problem of the failure of the poetry journal, specifically, its failure to excite or satisfy students, and by extension, the teacher (who expresses himself morally in terms of what students gain from his teaching). To stop the interview at this point and not find some pathway out either from the journal problem or the teaching problem it stands for, would be an acknowledgment that these problems are not actionable. Within educational theory and practice such a conclusion of despair is morally unacceptable. Educational discourse (and research) are always about making things better, never about leaving them bad or making them worse.

The momentum, then, is to 'go somewhere' in the interview beyond the matters acknowledged so far. Alan resurrects his 'going nowhere' theme to underline the necessity for change. His Discourse of moral responsibility becomes more positive and proactive. He does not yet specify what this change will be in terms of his English teaching. The topic of the poetry journal has been left behind. What he says is about students just being positioned and just sitting, an implied contrast with something more (not 'the end of the story'). Our analysis is making the case that in talking further, Alan is himself 'going places' by searching for a possible solution.

So I think you have far less trouble, marrying sociocultural [critical literacy] and new critical than you would with sociocultural and reader response because reader response doesn't expect you to be able to do anything much apart from have a soft, touchy, feely experience with the poem, you see, and then that makes it very hard because if you get a student who's only done touchy, feely stuff, they just can't do it because they don't know about being positioned because reader response says get positioned and have a wonderful time at it, you know, and just be positioned and just sit amongst the positioning and there you are and that's the end of the story, you know what I mean, there's no, it's like watching television, you know, nothing 
happens and I hate I can't stand that and because then you read the stuff, the stuff that the kids come out with is just awful. What is the purpose? It doesn't get them anywhere because it well, surely, here I'm being, I'm putting my thoughts about the value of teaching English and stuff here but, I can't see the point in getting someone (pause) say someone who's very young and hasn't - kids are growing up and stuff and if you get someone who's very young and they read a poem and all they get out of the poetry is um, a reinforcement of problems that they have, and they're not given any doors, or any windows onto a wider experience or more possibilities [...] (Interview 2, 472-494)

Alan's use of the metaphor of his poetry teaching as opening 'windows onto a wider experience or more possibilities' is important in his claims to moral responsibility given the recognitions and the accounting that have gone on so far. The metaphor of opening doors or windows sets up a rhetorical opposition with another metaphor, 'leaving them in the dark' which Alan used earlier in this conversation. This contrast does similar work to 'going places' versus 'just sitting'. The opposition of these pairs of movement metaphors frames pedagogical choices and constructs and represents a conflict within his morally accountable responsibility. To illustrate further how dense is the metaphoric language he uses at the end of this interview:

R: You're saying, what you're criticising there is the notion of reader response asking them to identify and analogise the

A: Yes and no further. So they can think the poem, they can finish with that poem and be no further in their life experience or their English experience or their knowledge experience, nothing has changed, and so it's um, the person is closed because all they will accept from the poetry is what they already have. You know if they have very little they will get very little from the poetry or any text anywhere and you would send the children out into the world with nothing, because they could sit in the midst of a whole kaleidoscopic range of literary stimulus, and only receive the same ones that they were receiving when they were a child and that's not fair, it's not really fair to the children. If either, whether you teach new criticism or you teach sociocultural [critical literacy] at least you're going to open doors, and let that kaleidoscopic range of stimulus in, at least they would be receptive to it hopefully. (Interview 2: 500-519)

\section{Concluding Comments}

The act of talking through different ways of doing English teaching just might be moving this teacher's practice from one form to another, although we cannot say from this material which doors will be opened or shut. Whether or not some correction is or can be made to the poetry journal is not the central outcome we are concerned about, and is in a sense immaterial to this argument. Whatever the practical outcome, this talk produces a difference, a distance, a gap between forms of pedagogic practice and has connected a sense of moral consequentiality to these options. What has happened here is not equivalent to Alan talking into 
a tape or otherwise 'reflecting' on his practice alone. The presence of the researcher-colleague is undoubtedly part of any shift that could be taking place.

Alan appreciated that he was not telling a complete or unified story about his English teaching. Towards the end of the second interview he offers the comment 'I haven't thought about this before. I' $m$ finding it rather interesting'. (Interview 2,498 ). With this comment Alan shows that he is making it all up on the spot because he is being asked to talk about it, now. Here he is accounting for his performance in the talk itself. More directly pertinent to the main purposes of this paper, however, is that the talk itself needs to be seen as a consequential material event in the organisation of Alan's professional practice. It is not 'just talk' which happens and disappears (although in this case it was recorded). It is not only talk about practice (either retrospective or prospective); it is a form of professional practice in itself. Whether or not such talk materialises in changed classroom practice is not the point in this paper.

It is the extended talk that produced the status of the poetry journal assessment as being dissatisfying to Alan and his students. This extending was done because the talk was interactional, had a partly-shared history to refer to, and was strongly purposeful, seeking the teacher's accounts and oriented to what the teacher might do. Retrospective accounts were shown to be contrasted with either stated or implied alternative prospective courses of action. Both were encompassed in the post-lesson conversation. This was a form of 're-search' (looking for again) by both interviewer and teacher. Our analysis put accounting at the centre of the teacher's work in the post-lesson conversation. This accounting is situated, pragmatic and oriented to moral considerations. Talk about teaching (one's own or someone else's) produces versions of morally accountable action because teaching is at the centre a practice that combines care and control (McLaughlin, 1991; Johnson, 1996). Accounting is a much more powerful way of describing what the teacher is doing in this interview than some term such as 'reporting' or 'reflecting', both of which could exclude the interviewer as primary recipient of the teacher's work in making sense of his past and future teaching. Such an analysis of accounting gives a clearer, sharper conceptualisation of the institution and culture of teaching. Culture is 'internal to action' (Hester \& Eglin, 1997b:154). It 'is not just that members use culture to do things, but that culture is constituted in, and only exists in, action' (Hester \& Eglin, 1997a: 20). Talk is situated action; and professional talk is situated professional action: pedagogic practice.

\section{References}

Atkinson, J. and Drew, P. (1979) Order in Court: The Organisation of Verbal Interaction in Judicial Settings. London: Macmillan.

Baker, C. and Keogh, J. (1995) Accounting for achievement in parent-teacher interviews. Human Studies 18 (2/3), 263-300.

Baker, C.D. (1997) Membership categorisation and interview accounts. In D. Silverman (ed.) Qualitative Research: Issues of Theory and Method (pp. 130-43). London: Sage.

Briggs, C. (1986) Learning How to Ask: A Sociolinguistic Appraisal of the Role of the Interview in Social Science Research. Cambridge, MA: Cambridge University Press.

Gee, J.P. (1996) Social Linguistics and Literacies: Ideologies in Discourses (2nd edn). London: Taylor \& Francis.

Hester, S. and Eglin, P. (1997a) Membership categorisation analysis: An introduction. In 
